\title{
The influence of pregnancy on the sensitivity of the cornea
}

\author{
MICHEL MILLODOT \\ From the Department of Optometry, University of Wales Institute of Science and Technology
}

SUMMARY Corneal touch thresholds (CTT) were measured in 30 non-pregnant women serving as a control group and 29 pregnant women at different times during and after pregnancy. The results show that CTT becomes significantly higher after 31 weeks of pregnancy. However, only $86 \%$ of the subjects showed a difference in CTT during and after pregnancy, while $52 \%$ reported having some swelling. The loss of sensitivity $\left(\mathrm{CTT}^{-1}\right)$ is assumed to be related to the water retention occurring during pregnancy, a view which is supported by some measurements of corneal thickness. It is suggested that this study may have exposed a new, hitherto unknown, way of monitoring pregnant women.

Corneal sensitivity has been shown by Millodot and Lamont (1974) to decrease during the premenstrual phase of the woman's menstrual cycle. Many of the changes occurring during the premenstrual phase are similar to those of pregnancy (Best and Taylor, 1945). Hence it was felt that corneal sensitivity may also be affected in pregnant women, especially when hydration is manifest, since it is known that corneal oedema gives rise to a loss of corneal sensitivity (Millodot, 1975a). The purpose of this study is to report changes in corneal sensitivity taking place in many normal pregnant women.

\section{Material and methods}

The Cochet-Bonnet aesthesiometer (Cochet and Bonnet, 1960) based on the instrument devised by Boberg-Ans (1955) was used to stimulate the cornea. The instrument consists of a nylon monofilament of $0.12 \mathrm{~mm}$ diameter which can produce pressures ranging from 11 to $200 \mathrm{mg} / 0.0113 \mathrm{~mm}^{2}$. The aesthesiometer was mounted in a holder so that it could be moved in $x, y$, and $z$ planes by means of three knobs. Thus, it was possible to achieve reliability in stimulation of the same corneal point, a steady speed of application, and a perpendicular corneal contact. A corneal point near the lower limbus was stimulated, and the slightest bend of the nylon wire was defined as corneal contact while the subject fixated a target in front and above her. The peripheral corneal point was chosen because

Address for reprints: Professor M. Millodot, Department of Optometry, UWIST, Cardiff CF1 3NU. the touch threshold measured there is usually unaffected by apprehension factors (Bonnet and Millodot, 1965).

Measurements of corneal touch threshold (CTT) were made subjectively (Millodot, 1973). The experiment began with the lowest pressure and continued in an ascending fashion. At each predetermined length of the monofilament (with ir.crements equal to $0.5 \mathrm{~cm}) 4$ to 6 contacts were made with at least one blank to test the subject's reliability. The subject indicated when she felt the probe by operating a bell. From these measurements CTT was defined as the length of the monofilament at which the subject responded for $50 \%$ of the number of stimulations. This length was converted into pressure by means of a previously calibrated curve for the instrument. All measurements were taken when the humidity in the room ranged between 50 and $60 \%$ because the nylon monofilament is affected by humidity.

Twenty-nine normal pregnant women between 22 and 39 years old (mean 28.2; SD 3.6) participated in this investigation in response to an advertisement. All were in good health, and it is thought that none of them came from a low socioeconomic background. Each subject was asked whether she had noted any swelling, particularly of the ankles and fingers. All were tested at least once but many of them several times during pregnancy ( 1 of them every month from the third month onwards). CTT was measured again between 6 and 8 weeks after delivery. Care was taken to ensure that these measurements were carried out at about the same time of day with each individual to avoid confound- 
ing the results with the diurnal variation of corneal sensitivity (Millodot, 1972).

In addition a control group of 30 non-pregnant women aged between 21 and 40 were tested once in the same conditions as the pregnant women.

\section{Results}

The measurements obtained with the control group are shown in Fig. 1. The spread of the results confirms earlier measurements (Millodot, 1973). It is attributable to inherent biological differences and differences in eye colour (Millodot, 1975b).

The results for the pregnant women are also given in Fig. 1 as well as after delivery. The figure illustrates the fact that most pregnant women tended to have a higher CTT (that is a lower sensitivity) with advancing pregnancy, especially in the final phase. However, the difference in CTT between the control group of non-pregnant women and the pregnant women becomes statistically significant only in the 31 to 40 weeks range $(t=2.93, \mathrm{P}<0.01)$.

It is worth pointing out that only 25 of the 29 $(86 \%)$ pregnant women showed a difference in CTT $(>10 \%)$ at some stage during pregnancy as compared to after delivery. Interestingly, those who had the greater increase in CTT appeared to be overweight for their height, a fact which corroborates other observations (Thomson et al., 1967). Of these 25 subjects 15 reported slight swelling of either their ankles or fingers or both. In other words 15 of the 29 pregnant women $(52 \%)$ had some symptoms. It must be noted that all these subjects were seen at

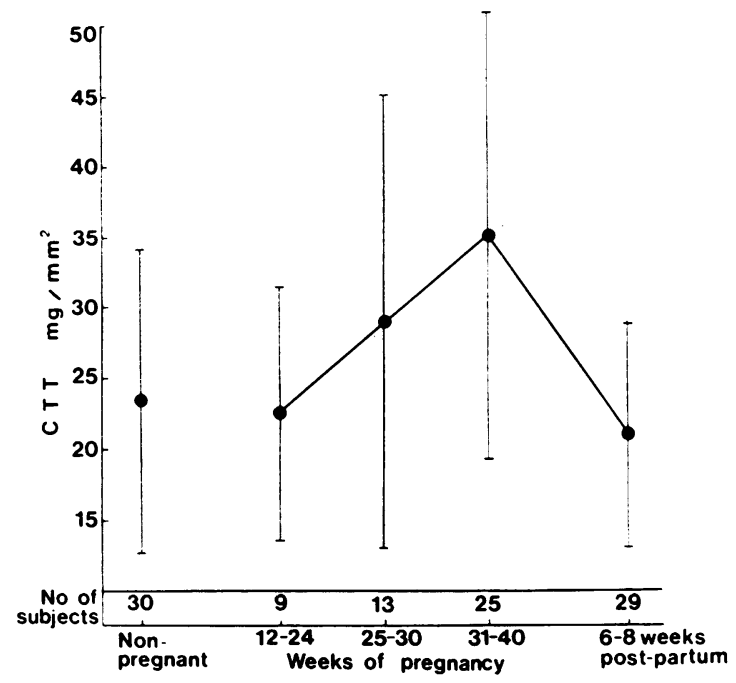

Fig. 1 Mean corneal touch threshold (CTT) in a control group of non-pregnant women and in pregnant women during pregnancy and after delivery. The vertical lines represent \pm 1 standard deviation

odd times during pregnancy; had they been tested throughout gestation this last figure might have been greater. As a corollary the figure $86 \%$ might also have been higher. All 4 women who had no difference in CTT reported having had no swelling either.

Six to eight weeks post-partum CTT had returned to normal in all subjects and there was no significant difference between this group and the control group of non-pregnant women $(t=1 \cdot 8, \mathrm{P}>0 \cdot 1)$.

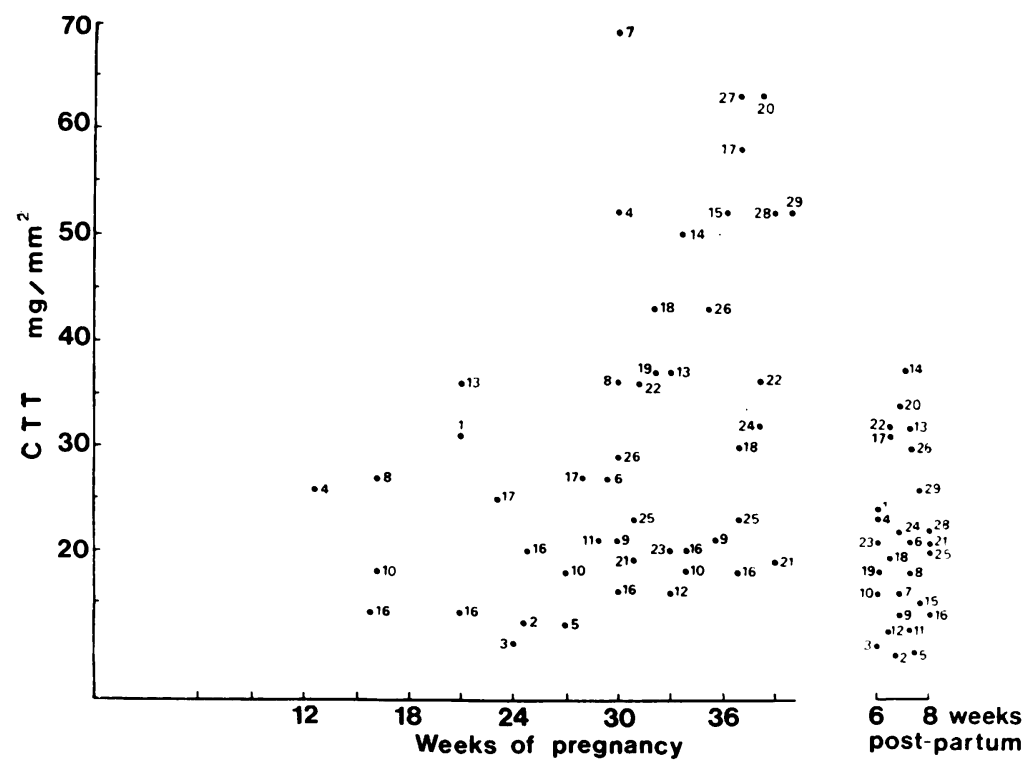

Fig. 2 Individual measurements of corneal touch threshold during and after pregnancy. Each subject is indicated by the number placed next to each data point 
CORNEAL THICKNESS

Since there seems to be a relationship between the loss of corneal sensitivity and swelling in pregnancy, it was thought that the cornea may also become oedematous. It has already been shown that corneal oedema accompanies the changes occurring in corneal sensitivity as a result of contact lens wear (Millodot, 1975a). Thus corneal thickness, which is an index of corneal oedema (Mishima and Hedbys, 1968), was measured in 5 pregnant women when their CTT was appreciably above normal. Measurements of central corneal thickness were made with a Haag-Streit slit-lamp 900 and pachometer. The results are given in Table 1 . They provide some evidence of corneal oedema in pregnant women, though it is quite slight. Moreover, the amount of corneal oedema appears to be unrelated to the severity of corneal sensitivity loss.

\section{Discussion}

The decline in corneal sensitivity demonstrated in this study parallels the increasing weight and water retention known to occur in pregnancy (Hytten and Leitch, 1971). The fact that some increase in corneal thickness was found supports the view that the cornea also was oedematous. But the slight increase in corneal thickness, uncorrelated to the loss of corneal sensitivity, may indicate that the reduction in the sensitivity of pregnant women's corneas may involve some other changes taking place at a higher level. However, the greatest losses of corneal sensitivity were usually found in women who reported swelling of their ankles or fingers or both.

The fact that only $52 \%$ of the pregnant women reported some swelling (mostly slight) seems somewhat low as compared to the observations of Robertson (1971). He found that $83 \%$ of pregnant women, whom he tested throughout pregnancy,

Table $1 C T T\left(\mathrm{mg} / \mathrm{mm}^{2}\right)$ and corneal thickness $(\mathrm{mm})$ measured in 5 pregnant women at some time (weeks) during pregnancy and 6 to 8 weeks after delivery

\begin{tabular}{lllllll}
\hline & & & \multicolumn{2}{l}{ During pregnancy } & \multicolumn{2}{l}{ After delivery } \\
\cline { 4 - 7 } $\begin{array}{l}\text { Case } \\
\text { No. }\end{array}$ & Time & CTT & $\begin{array}{l}\text { Corneal } \\
\text { thickness }\end{array}$ & Symptoms & CTT & $\begin{array}{c}\text { Corneal } \\
\text { thickness }\end{array}$ \\
\hline 17 & 37 & 58 & 0.58 & Fingers swollen & 31 & 0.53 \\
22 & 36 & 36 & 0.57 & None & 32 & 0.54 \\
27 & 37 & 63 & 0.60 & Ankles and & 16 & 0.56 \\
28 & 39 & 52 & 0.57 & Ankles swollen & 21 & 0.53 \\
29 & 40 & 52 & 0.58 & Fingers swollen & 24 & 0.53 \\
\hline
\end{tabular}

reported swelling at some stage. But, as noted earlier, the low figure obtained here may be explicable by the fact that the pregnant women were seen only at odd times during gestation. It is interesting, though, that by testing corneal sensitivity $86 \%$ of the pregnant women showed a difference from their sensitivity after delivery. And since loss of corneal sensitivity always accompanies corneal oedema, however slight (Millodot, 1975a), the results of this study may be regarded as providing evidence supporting Robertson's claim (1971) that increased hydration may be universal in normal pregnancy.

The increase in corneal touch threshold in pregnant women has apparently never been reported before. It offers an alternative means of monitoring the progress of pregnancy. Moreover, it is quantifiable and may be an early detector, since a much higher percentage of pregnant women was thus detected than by asking the patient. And in all cases but one high CTTs were accompanied by a report of swelling. The monitoring of pregnancy by this method could be useful in preventive therapy.

The loss of corneal sensitivity during pregnancy cannot account for the difficulty encountered by some women in wearing their contact lenses. It is more likely to be due to a variation in corneal topography as a result of oedema. An alteration of the composition of the tears may also occur, as these patients often complain that their lenses become greasy soon after they have been inserted in the eyes. Indeed, lysosyme, which is a viscous component of the tears, is secreted in greater quantity when there is generalised oedema (Moses, 1970).

Since a change in the topography will alter the power of the eye, and since corneal oedema leads to a change in corneal index (Fatt and Harris, 1973), it is not advisable to prescribe a new optical correction until some weeks after delivery.

Finally, it should be noted that a slight decrease in intraocular pressure (IOP) has been observed during pregnancy (Marx, 1923; Hørven and Gjønnaess, 1974). Although it is known that there is a reduction in corneal sensitivity with an increase in IOP (Boberg-Ans, 1955), it is not known whether a decrease in IOP would induce the same effect. The present results suggest that a fine balance in IOP may be needed for corneal sensitivity to remain unaltered.

References

Best, C. H., and Taylor, N. B. (1945). The Physiological Basis of Medical Practice, 4th edn., pp. 746-749. Williams \& Wilkins: Baltimore.

Boberg-Ans, J. (1955). Experience in clinical examination of corneal sensitivity. British Journal of Ophthalmology, 39, 705-726. 
Bonnet, R., and Millodot, M. (1965). L'esthésie cornéenne, sa mesure dans l'obscurité. Clinique Ophtalmologique, 6, 74-78.

Cochet, P., and Bonnet, R. (1960). L'esthésie cornéenne. Clinique Ophtalmologique, 4, 3-27.

Fatt, I., and Harris, M. G. (1973). Refractive index of the cornea as a function of its thickness. American Journal of Optometry, 50, 383-386.

Hørven, I., and Gjønnaess, H. (1974). Corneal indentation pulse and intraocular pressure in pregnancy. Archives of Ophthalmology, 91, 92-98.

Hytten, F. E., and Leitch, I. (1971). The Physiology of Human Pregnancy, 2nd edn., pp. 345-355. Blackwell Scientific Publications: Oxford.

Marx, E. (1923). Influence de la menstruation et de la grossesse sur la tension oculaire. Annales d'Oculistique, 160, 873-882.

Millodot, M. (1972). Diurnal variation of corneal sensitivity. British Journal of Ophthalmology, 56, 844-847.

Millodot, M. (1973). Objective measurement of corneal sensitivity. Acta Ophthalmologica, 51, 325-334.
Millodot, M. (1975a). Effect of hard contact lenses on corneal sensitivity and thickness. Acta Ophthalmologica, 53, 576-584.

Millodot, M. (1975b). Do blue-eyed people have more sensitive corneas than brown-eyed people? Nature, 255, 151-152.

Millodot, M., and Lamont, A. (1974). Influence of menstruation on corneal sensitivity. British Journal of Ophthalmology, 58, 752-756.

Mishima, S., and Hedbys, B. O. (1968). Measurement of corneal thickness with the Haag-Streit pachometer. Archives of Ophthalmology, 80, 710-713.

Moses, R. A. (1970). Adler's physiology of the Eye, 5th edn., p. 21. C. V. Mosby: St. Louis.

Robertson, E. G. (1971). The natural history of oedema during pregnancy. Journal of Obstetrics and Gynaecology of the British Commonwealth, 78, 520-529.

Thomson, A. M., Hytten, F. E., and Billewicz, W. Z. (1967). The epidemiology of oedema during pregnancy. Journal of Obstetrics and Gynaecology of the British Commonwealth, 74, 1-10. 